\title{
Preemptive Midazolam Can Reduce the Glycemic Stress Response to Surgery for Type-2 Diabetics Undergoing Simple Eye Surgery
}

\author{
ASHRAF E. ABDALLA, M.D.; MAHMOUD M. ELSAYED, M.D. and ABDALLA M. ELSAYED, M.D. \\ The Department of Anesthesia, Faculty of Medicine, Al-Alzher University, Cairo, Egypt
}

\begin{abstract}
Background: Estimation of percentage of change of blood glucose concentration (BGC) at 30- and 60-min after single dose of intravenous midazolam injection and at end of surgery in relation to pre-injection concentration.
\end{abstract}

Aim of Study: Estimation of percentage of changes of blood glucose concentration (BGC) at 30- and 60-min after intravenous injection of single dose of midazolam and at end of surgery in relation to pre-injection BGC.

Patients and Methods: 100 type-2 diabetic patients with fasting BGC of $\geq 200 \mathrm{mg} / \mathrm{dl}$, ASA grade II or III and assigned for cataract surgery were evaluated clinically and received midazolam injection in a dose of $0.01-0.1 \mathrm{mg} / \mathrm{kg}$, up to a total dose of $2.5 \mathrm{mg}$, over two minutes or until patient was sedated and achieved Ramsy score 2 or 3 . BGC was estimated before midazolam injection and at 30-min, 60-min after injection and at end of surgery. Then, patients received peribulbar and subtenon local anesthetic infiltration was performed.

Results: All surgeries were conducted uneventfully within a mean operative time of $62.6 \pm 8.8 \mathrm{~min}$. BGC showed progressive increases during surgery reaching a maximum at 60 -min after injection and declined at end of surgery, but with nonsignificant differences between the three estimations and the pre-injection levels. Median value of percentage of increase of BGC at 60-min was significantly higher in comparison to median values of other estimations, with significantly higher percentage of increase at end of surgery than at 30-min after injection.

Conclusion: Preemptive administration of midazolam for diabetic patients could control the surgery-induced hyperglycemic effect and thus could protect patients against postoperative hyperglycemic complications.

Key Words: Midazolam - Type-2 Diabetes mellitus - Surgical stress - Percentage of change.

\section{Introduction}

DIABETES prevalence is increasing all over the world and is affected by the risk of developing diabetes mellitus (DM) and survival of diabetics

Correspondence to: Dr. Ashraf E. Abdalla, The Department of Anesthesia, Faculty of Medicine, Al-Alzher University, Cairo, Egypt
[1]. Fasting blood glucose (FBG) values of $<100 \mathrm{mg}$ /dl were considered normal, while values of $100-$ $125 \mathrm{mg} / \mathrm{dl}$ indicate impaired fasting glucose concentration and DM was defined as FBG of $\geq 126 \mathrm{mg}$ $/ \mathrm{dl}[2]$

Diabetes-related microvascular complications involving nerves, eyes, kidneys and feet significantly impact patients with type-2 diabetes (T2D) and are associated with increased morbidity and mortality [3]. Pathogenesis of microvascular complications could be attributed to the oxidative and nitrosative stress occurred secondary to hyperglycemia and resulted in endothelial and microvascular dysfunction [4].

Perioperative hyperglycemia is associated with increased morbidity and mortality [5]. Regarding the intraoperative hyperglycemia, no difference in postoperative outcomes was detected between intraoperative blood glucose levels of more or less than $180 \mathrm{mg} / \mathrm{dl}$ but intraoperative blood glucose of $250 \mathrm{mg} / \mathrm{dL}$ was a predictor of 30-day mortality/ morbidity [6].

Anesthesia and surgery can aggravate diabetic patient and increase the incidence of complications secondary to poor blood glucose control, so decreasing glucose variability during admission for surgery is essential to reduce re-admission rates and length of stay of T2D patients [7]. The type and regimen of anesthesia may affect perioperative hyperglycemia following major surgical stress $[8,9]$. The effect of perioperative anesthetics on the blood glucose level of diabetic patients will play an essential role in the postoperative recovery of patients [7].

The benzodiazepine midazolam (MDZ) is commonly used as first-line treatment in patients with acute seizures and for procedural sedation and during general anesthesia [10]. Midazolam is a 
benzodiazepine receptor agonist that causes sedation through activation of GABA A receptors [11] that requires predominance of the $\mathrm{K}^{+-} \mathrm{Cl}$ cotransporter isoform 2 to cause influx of $\mathrm{Cl}$ - and subsequent neuronal hyperpolarization [12]. GABAergic effect of midazolam promotes its sedative, anxiolytic, and anticonvulsant properties and is characterized by the fast onset and short duration of action than other benzodiazepines [13]. Midazolam is used for pediatric procedural sedation for provision of minimal sedation, fast onset and rapid recovery [14]. However, the effects of midazolam on metabolic and endocrinal surgical stress response were poorly, so the current placebo-controlled study tried to evaluate these effects.

\section{Patients and Methods}

This prospective comparative study was conducted at Anesthesia Department, Alhada Military Hospital, Taif, KSA, since June 2019 till Jan 2020. After approval of the study protocol by the Local Ethical Committee, all type-2 diabetic patients and assigned for cataract surgery were eligible for evaluation.

The inclusion criteria included simple eye operation, age $>50$ years, type- $2 \mathrm{DM}$, ASA grade II or III and signed written fully informed consent to participate in the study. All patients were evaluated for demographic and clinical data for assurance of inclusion and exclusion criteria. All patients gave blood sample, at time of arrival to the hospital, for estimation of fasting (FBG) concentration and patients with FBG level of $\geq 200 \mathrm{mg} / \mathrm{dl}$ were included in the study. All enrolled patients received slow intravenous midazolam injection in a dose of 0.01$0.1 \mathrm{mg} / \mathrm{kg}$, up to a total dose of $2.5 \mathrm{mg}$, over two minutes or until patient was sedated and achieved Ramsy score 2 or 3 . BGC was re-estimated at 30min, 60-min after midazolam injection and at end of surgery. After patient was sedated (Ramsy score of 2-3), peribulbar and subtenon local anesthetic infiltration was performed.

\section{Study outcome:}

The study outcome was the change of blood glucose concentration after midazolam injection in relation to baseline preoperative levels and to corresponding estimations in control patients.

\section{Statistical analysis:}

Data are presented as mean, standard deviation (SD), numbers, percentages, median and interquartile range (IQR). Parametric results were analyzed using paired $t$-test for comparisons of estimated BGC pre- and post-injection and non-parametric results were analyzed using Chi-square test and
Mann-Whitney test. Statistical analysis was conducted using IBM $®$ SPSS $®$ Statistics (Version 22, 2015; Armonk, USA) for Windows statistical package. $p$-value $<0.05$ was considered statistically significant.

\section{Results}

The study included 123 patients; 23 patients were excluded for not fulfilling the inclusion and 100 patients were included in the study (Fig. 1). Demographic and clinical data of enrolled patients were shown in Table (1). All surgeries were conducted uneventfully within a mean operative time of 62.6 \pm 8.8 (range: 55-80) min.

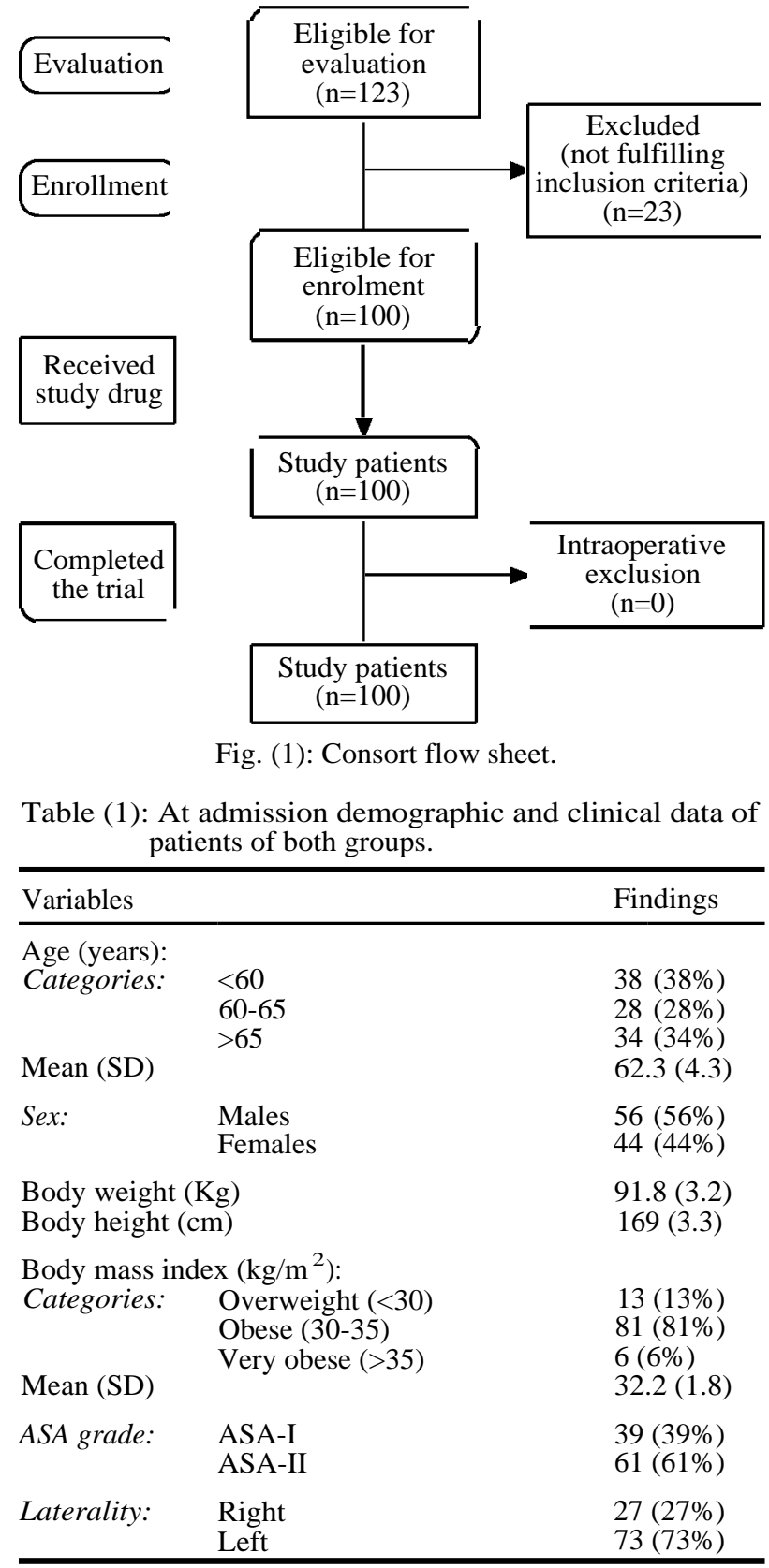

Data are shown as mean, standard deviation (SD), numbers, percentages. 
Blood glucose levels showed progressive increases during surgery reaching its summit at 60-min after injection and declined at end of surgery. However, estimated BGC at 30-min and 60-min after injection and at end of surgery were non-significantly higher in comparison to preoperative concentration with non-significantly higher concentration at 60min after injection in comparison to that estimated at 30-min and at end of surgery. Moreover, BGC estimated at end of surgery were non-significantly higher in comparison to that estimated at 30-min after injection (Table 2, Fig. 2).
Regarding the percentage of increase of BGC after midazolam injection in comparison to preoperative levels, median value of increase of BGC at 60-min after injection was significantly higher in comparison to the median value of percentage of increase at 30-min after injection and at end of surgery. Moreover, the median value of percentage of increased BGC at end of surgery was significantly higher in comparison to that recorded at 30-min after injection (Table 2, Fig. 3).

Table (2): BGC estimated at 30- \& 60-min after midazolam injection and at end of surgery.

\begin{tabular}{|c|c|c|c|c|}
\hline Variable Time & Pre-injection & 30-min after injection & 60 -min after injection & End of surgery \\
\hline $\begin{array}{l}\text { Blood glucose level: } \\
\text { Mean }( \pm \mathrm{SD})\end{array}$ & $223.3 \pm 17.5$ & $227.9 \pm 17.3$ & $231.6 \pm 20.2$ & $229.6 \pm 17.4$ \\
\hline $\begin{array}{c}p \text {-value: } \\
p_{1} \\
p_{2} \\
p_{3}\end{array}$ & & 0.105 & $\begin{array}{l}0.069 \\
0.492\end{array}$ & $\begin{array}{l}0.087 \\
0.791 \\
0.594\end{array}$ \\
\hline $\begin{array}{l}\text { \% of change of blood glucose: } \\
\text { Median } \\
\text { IQR }\end{array}$ & $\begin{array}{l}- \\
-\end{array}$ & $\begin{array}{l}1.78 \\
1.33-2.97\end{array}$ & $\begin{array}{l}3.65 \\
2.26-5.36\end{array}$ & $\begin{array}{l}2.9 \\
1.47-3.98\end{array}$ \\
\hline $\begin{array}{c}p \text {-value: } \\
p_{2} \\
p_{3}\end{array}$ & & & $<0.001$ & $\begin{array}{l}<0.001 \\
0.006\end{array}$ \\
\hline
\end{tabular}

Data are shown as mean, standard deviation (SD), median; Interquartile range (IQR); $p 1$ : Indicates significance of difference between BGC estimated at 30- \& 60-min after midazolam injection and at end of surgery in comparison to pre-injection concentration; $p 2$ value indicates significance of difference between BGC estimated at 60-min after midazolam injection and at end of surgery in comparison to estimates recorded at 30-min after midazolam injection; $p 3$ value indicates significance of difference between levels estimated at 60-min after midazolam injection versus that estimated at end of surgery; $\quad p<0.05$ indicates significant difference; $p$-value $>0.05$ indicates non-significant difference.

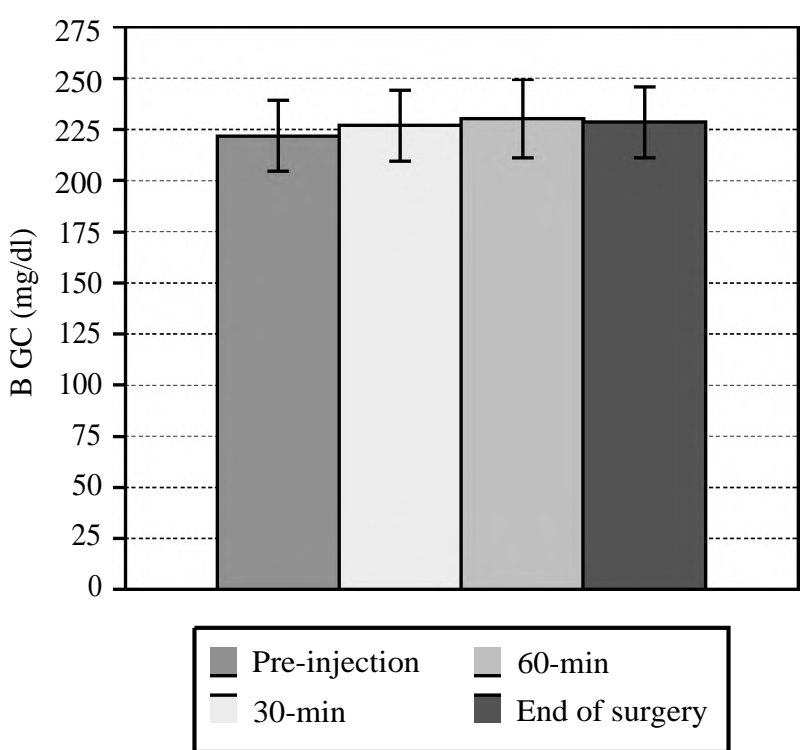

Fig. (2): Mean BGC estimated in studied patients at preinjection and 30- \& 60-min after injection and at end of surgery.

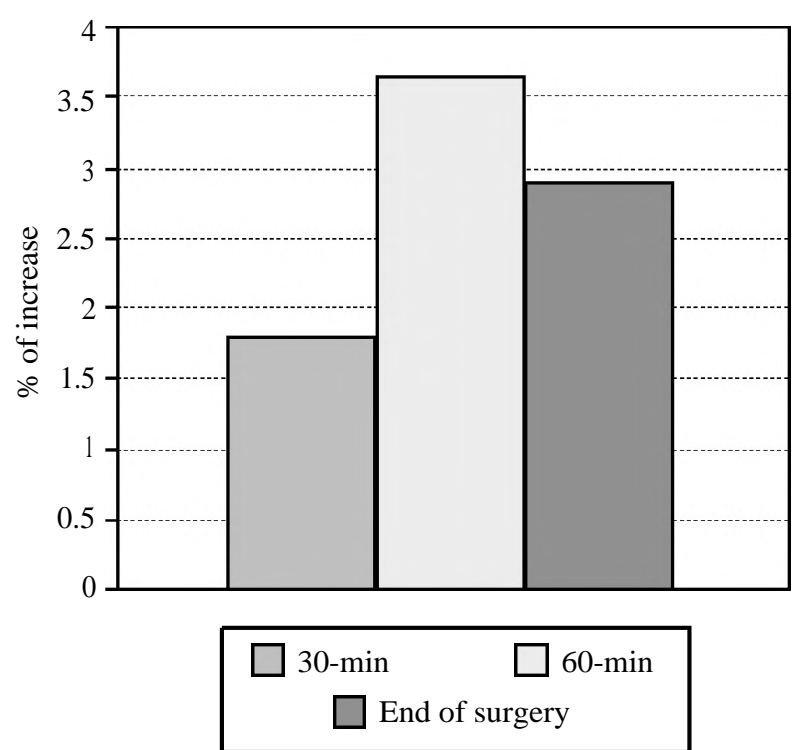

Fig. (3): Median percentage of increase of BGC after midazolam injection. 


\section{Discussion}

The study hypothesis was that single dose of midazolam could modulate the glycemic stress response to ocular surgery requiring operative duration of about 60 minutes. The obtained results assured that hypothesis where BGC estimated at 30- and 60-minutes after midazolam injection and at end of surgery were non-significantly higher in comparison to pre-injection levels. However, the percentage of change of BGC progressively increased with progress of surgery; a finding indicated the glycemic stress of surgery, irrespective of type of surgery. These results point to a possible controlling effect of midazolam on surgical glycemic stress response.

The obtained results supported that previously reported non-significant difference between different sedatives used for either pre-medication, induction or as adjuvant during anesthesia as regards the control of glycemic stress response to anesthesia and/or surgery $[\mathbf{1 5 , 1 6 , 1 7 ]}$. Moreover, the obtained results were superior to that obtained by Tilak et al., [18] who reported non-significant differences in the percent of increase in BGC between patients who received midazolam or placebo and concluded that preoperative administration of midazolam did not cause attenuation of the hyperglycemic response compared to the placebo group. In support of the efficacy of hyperglycemic controlling effect of midazolam, experimental midazolam injection was found to prevent hyperglycemia-induced generation of reactive oxygen species and subsequent vascular leakage in the retinas $[11,19]$ and lungs of diabetic mice.

The obtained results had multiple attributions; firstly, to the sympathetic blocking action of midazolam with subsequent decreased release of adrenaline, which is glucogenic hormone, and so minimization of glucogenic stress response to surgery. In line with this assumption, Sawaguchi et al., [20] detected more inhibition of sympathetic nervous activation induced by electrical stimulations with intravenous sedation using combination of midazolam and propofol than with propofol alone and Nishiyama [21] found midazolam pre-medication inhibited sympathetic activation at induction of anesthesia. Recently, Kurzová et al., [22] evaluated the effect of midazolam sedation on sympathetic activity as judged by changes in electrical skin impedance and detected highly significant differences between electrical skin impedance with midazolam sedation versus pretreatment impedance levels and versus placebo.
Secondly, the reported effect could be attributed to an agonizing effect of midazolam on GABA receptors on insulin resistance, which is coincident with type-2 diabetes mellitus [7], in support of this attribution, $\mathrm{Li}$ et al., [23] using type-2 DM animal model found supplementation by GABA-rich yogurt favorably regulated homeostasis model assessment of $\beta$-cell function, improved islet cells morphology and lowered total cholesterol in a dosedependent manner. Thereafter, Rezazadeh et al., [24] using animal model of type-2 DM found GABA therapy improved insulin resistance in diabetic animals by increasing the expression of GLUT4, the main glucose transporter to the cell, whereby glucose is metabolized with subsequent decrease of BGC. Moreover, Rezazadeh et al., [24] found GABA therapy is indirectly able to reduce insulin resistance possibly through the increased gene expressions of insulin receptor substrate 1 and a serine/threonine kinase. Clinically, Luc et al., [25] found whole-body cryostimulation in dementia patients causes decrease of insulin resistance through inducing alterations in gut microbiota, which produce neurotransmitters, such as GABA. Thirdly, midazolam may increase secretion of insulin by pancreatic $\beta$-cell as documented by Untereiner et al., [26] who showed that oral GABA administration to healthy animal model increased pancreatic $\beta$-cell mass leading to enhanced insulin secretion and glucose tolerance. Also, Tian et al. $[27,28]$ experimentally found the GABAA-R positive allosteric modulators work in conjunction with GABA secreted from $\beta$-cells to increase $\beta$-cell survival and replication [27] and treatment with GABAA-R agonists enhanced $\beta$-cell replication and survival in a human islet xenograft model [28] Interestingly, the controlling effect of midazolam on BGC had extended till the end of surgery and this supported previous works, which reported that midazolam can control surgery induced hyperglycemia during and till end of surgery [16,17]

\section{Conclusion:}

Preemptive administration of midazolam for diabetic patients could control the surgery-induced hyperglycemic effect and thus could protect patients against postoperative hyperglycemic complications.

\section{Limitations:}

The study was limited for evaluating the effect of preemptive midazolam on diabetic patients with fasting blood glucose of $\geq 200 \mathrm{mg} / \mathrm{dl}$ and for shortduration surgeries. 


\section{Recommendations:}

Wider scale comparative studies of midazolam versus other sedatives and for diabetic patients irrespective of their BGC are mandatory.

\section{References}

1- MAGLIANO D., CHEN L., ISLAM R., CARSTENSEN B., GREGG E., PAVKOV M. and ANDES L.: Trends in the incidence of diagnosed diabetes: A multicountry analysis of aggregate data from 22 million diagnoses in high-income and middle-income settings. Lancet Diabetes Endocrinol., Apr. 9 (4): 203-211. Doi: 10.1016/S22138587(20)30402-2, 2021

2- BITEKER M., DAYAN A., CAN M., ILHAN E., BITEKER F., TEKKESIN A. and DUMAN D.: Impaired fasting glucose is associated with increased perioperative cardiovascular event rates in patients undergoing major noncardiothoracic surgery. Cardiovasc. Diabetol., Jul. 14; 10: 63. Doi: 10.1186/1475-2840-10-63, 2011

3- REITZLE L., SCHMIDT V., DU Y., ICKS A., HAGEN B., ZIESE T. and SCHEIDT-NAVE C.: Estimating prevalent microvascular complications of diabetes mellitus in Germany. Analysis of statutory health insurance data in 2012 and 2013. Bundesgesundheitsblatt Gesundheits forschung Gesundheitsschutz, Oct. 63 (10): 1219-1230, 2020.

4- TESTA R., BONFIGLI A., PRATTICHIZZO F., La SALA L., De NIGRIS V. and CERIELLO A.: The "Metabolic Memory" Theory and the Early Treatment of Hyperglycemia in Prevention of Diabetic Complications. Nutrients, Apr. 28; 9 (5): 437. Doi: 10.3390/nu9050437, 2017.

5- SHANKS A., WOODRUM D., KUMAR S., CAMPBELL Jr D. and KHETERPAL S.: 2 Intraoperative hyperglycemia is independently associated with infectious complications after non-cardiac surgery. BMC Anesthesiol., Jul. 19; 18 (1): 90. Doi: 10.1186/s12871-018-0546-0, 2018.

6- SHAH N., LEIS A., KHETERPAL S., ENGLESBE M. and KUMAR S.: Association of intraoperative hyperglycemia and postoperative outcomes in patients undergoing non-cardiac surgery: A multicenter retrospective study. BMC Anesthesiol., May 7; 20 (1): 106. Doi: 10.1186/ s12871-020-01022-w, 2020.

7- XIONG X., CHEN C., CHEN H., GAO R., DENG Q., CAI X., LIANG P. and ZHU T.: Effects of intravenous and inhalation anesthesia on blood glucose and complications in patients with type 2 diabetes mellitus: Study protocol for a randomized controlled trial. Ann. Transl. Med., Jul. 8 (13): 825. Doi: 10.21037/atm-20-2045a, 2020.

8- GOTTSCHALK A., RINK B., SMEKTALA R., PIONTEK A., ELLGER B. and GOTTSCHALK A.: Spinal anesthesia protects against perioperative hyperglycemia in patients undergoing hip arthroplasty. J. Clin. Anesth., Sep. 26 (6): 455-60. Doi: 10.1016/j.jclinane.2014.02.001. Epub 2014 Sep 8. PMID: 25200644, 2014.

9- WANG J., QI J., WU Q., JIANG H., YIN Y., HUAN Y., ZHAO Y. and ZHU M.: Propofol attenuates high glucoseinduced P66shc expression in human umbilical vein endothelial cells through Sirt1. ActaBiochimBiophys Sin (Shanghai), Feb. 1; 51 (2): 197-203. Doi: 10.1093/abbs/ gmy167, 2019.
10- BOUW M., CHUNG S., GIDAL B., KING A., TOMASOVIC J., WHELESS J. and VAN ESS P.: Clinical pharmacokinetic and pharmacodynamic profile of midazolam nasal spray. Epilepsy Res., Mar. 171: 106567. Doi: 10.1016/j.eplepsyres.2021.106567, 2021.

11- LEE Y., KIM M., LEE J., JUNG S., JEON H., LEE S., KANG S., HAN E., PARK W., HONG S., KIM Y. and HA K.: The benzodiazepine anesthetic midazolam prevents hyperglycemia-induced microvascular leakage in the retinas of diabetic mice. FASEB J., May 21; fj201800014RR. Doi: 10.1096/fj.201800014RR, 2018.

12- DOI A., MIYAZAKI T., MIHARA T., IKEDA M., NIIKURA R., ANDOH T. and GOTO T.: CLP290 promotes the sedative effects of midazolam in neonatal rats in a KCC2-dependent manner: A laboratory study in rats. PLoS One, Mar. 12; 16 (3): e0248113. Doi: 10.1371/ journal.pone.0248113, 2021.

13- PROMMER E.: Midazolam: An essential palliative care drug. Palliat. Care Soc. Pract. Jan. 13; 14: 26323524 19895527. Doi: 10.1177/2632352419895527, 2020.

14- PICKTHORN S., TERPSTRA E., CONDE T., KOLBA J. and ALI M.: Use of Midazolam for Minimal Sedation in Pediatric Outpatients: A Survey Analysis of Patient Experience and Parent-Guardian Satisfaction. S D Med., Sep. 72 (9): 414-417, 2019.

15-OZTEKIN I., GÖKDOGAN S., OZTEKIN D., IS SEVER H., GÖKSEL O. and CANIK S.: Effects of propofol and midazolam on lipids, glucose, and plasma osmolality during and in the early postoperative period following coronary artery bypass graft surgery: A randomized trial. YakugakuZasshi. Jan. 127 (1): 173-82. Doi: 10.1248/ yakushi. 127.173, 2007.

16- KAVIANI N., KOOSHA F. and SHAHTUSI M.: Comparison of the changes in blood glucose level during sedation with midazolam and propofol in implant surgery: A prospective randomized clinical trial. J. Dent (Shiraz), Sep. 15 (3): 135-9, 2014.

17- KHALIGHINEJAD P., RAHIMI M., NAGHIBI K. and NIKNAM N.: Changes in blood glucose level during and after light sedations using propofol-fentanyl and midazolam-fentanyl in diabetic patients who underwent cataract surgery. Adv. Biomed Res., Oct. 7; (4): 222. Doi: 10.4103/ 2277-9175.166645, 2015 .

18- TILAK V., SCHOENBERG C., SUSAN B.G. and CHRISTINA A.: Does the Administration of Preoperative Midazolam Assist in Maintaining Blood Glucose Norms in the Non - Diabetic Patient during the Perioperative Period? Int. J. Anesth. Res., 4 (7): 278-283. DOI: dx.doi.org/ $10.19070 / 2332-2780-1600059$

19- SEO J., JEON H., KIM M., LEE Y., HAN E., PARK W., HONG W., KIM Y. and HA K.: Anti-metastatic effect of midazolam on melanoma $\mathrm{B} 16 \mathrm{~F} 10$ cells in the lungs of diabetic mice. Biochem. Pharmacol., Aug. 178: 114052. Doi: 10.1016/j.bcp.2020.114052, 2020.

20- SAWAGUCHI K., MATSUURA N. and ICHINOHE T.: Comparison of the Effect of Electrical Stimulations on the Chin Skin on Autonomic Nervous Activities During Propofol Sedation with or Without Midazolam. J. Oral Maxillofac Surg., Sep. 74 (9): 1751.e1-6. Doi: 10.1016/ j.joms.2016.03.040. Epub 2016 Apr 20. PMID: 27180023, 2016. 
21- NISHIYAMA T.: Effects of Premedication on Heart Rate Variability at Induction of Anaesthesia: Comparison between Midazolam and Hydroxyzine. Turk J. Anaesthesiol. Reanim. Jun. 46 (3): 229-232. Doi: 10.5152/ TJAR.2018.87059, 2018.

22- KURZOVÁ A., HESS L., SLÍVA J. and MÁLEK J.: Can changes in skin impedance be used to monitor sedation after midazolam and during recovery from anesthesia? Physiol. Res., Mar 8. Online ahead of print, 2021.

23- LI X., CHEN L., ZHU X., LU Z. and LU Y.: Effect of $\gamma$ aminobutyric acid-rich yogurt on insulin sensitivity in a mouse model of type 2 diabetes mellitus. J. Dairy Sci., Sep. 103 (9): 7719-7729. Doi: 10.3168/jds.2019-17757, 2020.

24- REZAZADEH H., SHARIFI M. and SOLTANI N.: Gamma-aminobutyric acid attenuates insulin resistance in type 2 diabetic patients and reduces the risk of insulin resistance in their offspring. Biomed Pharmacother., Jun. 138: 111440. Doi: 10.1016/j.biopha.2021.111440, 2021.

25- L'UC M., MISIAK B., PAWL'OWSKI M., STAN'CZYKIEWICZ B., ZABL'OCKA A., SZCZES`NIAK D., PAL'EGA A. and RYMASZEWSKA J.: Gut microbiota in dementia. Critical review of novel findings and their potential application. Prog Neuropsy chopharmacol. Biol.
Psychiatry, Jan. 10; 104: 110039. doi: 10.1016/j.pnpbp. 2020. 110039, 2021.

26- UNTEREINER A., ABDO S., BHATTACHARJEE A., GOHIL H., POURASGARI F., IBEH N., LAI M., BATCHULUUN B., WONG A., KHUU N., LIU Y., RIJJAL D., WINEGARDEN N., VIRTANEN C., ORSER B., CABRERA O., VARGA G., ROCHELEAU J., DAI F. and WHEELER M.: GABA promotes $P$-cell proliferation, but does not overcome impaired glucose homeostasis associated with diet-induced obesity. FASEB J., Mar. 33 (3): 3968-3984. Doi: 10.1096/fj.201801397R, 2019.

27- TIAN J., DANG H., KARASHCHUK N., XU I. and KAUFMAN D.: A Clinically Applicable Positive Allosteric Modulator of GABA Receptors Promotes Human P-Cell Replication and Survival as well as GABA's Ability to Inhibit Inflammatory T Cells. J. Diabetes Res., Feb. 26; 2019: 5783545. Doi: 10.1155/2019/5783545, 2019.

28- TIAN J., DANG H., O'LACO K., SONG M., TIU B., GILLES S., ZAKARIAN C. and KAUFMAN D.: Homotaurine Treatment Enhances CD4 + and CD8 + Regulatory T Cell Responses and Synergizes with Low-Dose AntiCD3 to Enhance Diabetes Remission in Type 1 Diabetic Mice. Immunohorizons, Oct. 21; 3 (10): 498-510. Doi: 10.4049/immunohorizons.1900019, 2019.

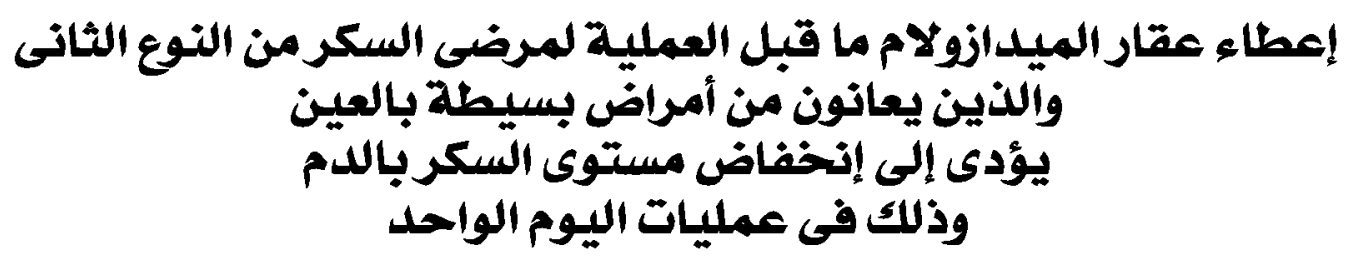

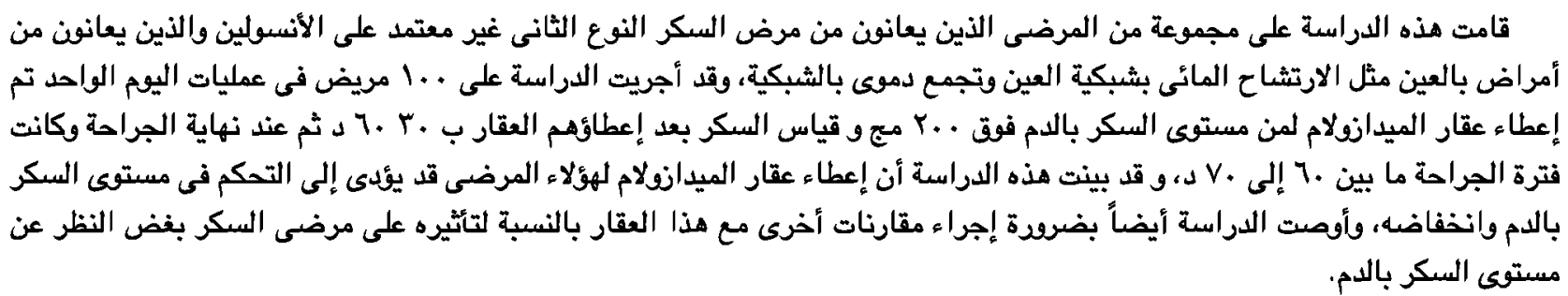

